\title{
Regulation of Melatonin Secretion in a Photoreceptive Pineal Organ: An in vitro Study in the Pike
}

\author{
Jacky Falcón, ${ }^{1}$ Jocelyne Brun Marmillon, ${ }^{2}$ Bruno Claustrat, ${ }^{2}$ and Jean-Pierre Collin ${ }^{1}$ \\ 1 Laboratoire de Biologie Cellulaire, URA CNRS 90, UFR Sciences, 86022 Poitiers Cédex, France, and ${ }^{2}$ Service de \\ Radiopharmacic ct Radioanalyse, Centre de Médecine Nucléaire, Hôpital Neuro-Cardiologique, 69394 Lyon Cédex 03, \\ France
}

The pineal organ (or pineal) of a teleost fish, the pike, contains typical (cone-like) and modified photoreceptor cells. Both are involved in indole metabolism, including melatonin production. How photoperiod controls melatonin biosynthesis in organs containing mainly photoreceptor cells, remains unclarified. To tackle this question we have used cultured pike pineal organs to investigate the variations in (1) the activity of the arylalkylamine- $\mathrm{N}$-acetyltransferase (NAT), which is involved in the biosynthesis of melatonin, in static culture and (2) melatonin release in a perifusion system. Serum melatonin was also quantified in pike kept under a $24 \mathrm{hr}$ light/dark (LD) cycle.

Under LD conditions, NAT activity, melatonin release, and serum melatonin levels were high during the scotophase and low during the photophase. High-amplitude rhythms in NAT activity and melatonin release were maintained during three $24 \mathrm{hr}$ cycles in constant darkness and a low-amplitude rhythm of NAT persisted in constant illumination. Midnight illumination induced a dramatic decrease of NAT activity and melatonin release. Darkness at midday did not induce a rise of the melatonin release, which occurred only at the onset of the subjective scotophase.

From the present data it is strongly suggested that the pineal of the pike contains a circadian oscillator-synchronized by the photoperiod-which generates the rhythms of NAT activity and of melatonin release. Melatonin release, which reflects the rhythmic activity of NAT, might largely contribute to the melatonin circulating levels. The circadian oscillations observed under constant conditions suggest that the oscillator might behave differently in the pike, compared with intrapineal oscillators of 2 other species (lizard and chicken) under investigation. Because pineal photoreceptors of the pike are both directly photosensitive and responsible for melatonin biosynthesis, we also suggest that they play a crucial role in the mechanisms of translation of photoperiodic information into melatonin via an intrapineal oscillator that remains to be localized.

Received June 3, 1988; revised Sept. 22, 1988; accepted Sept. 28, 1988

This work was supported by the CNRS (URA 90), INSERM (Grant 876007) and the Fondation Langlois, Rennes, France. We wish to thank F. Chevalier, J. Guerlotté, and P. Voisin for their help and D. Decourt for typing the manuscript. We also express our deep thanks to Dr. F. Gonnet, who showed us his perifusion system.

Correspondence should be addressed to Dr. Jacky Falcón, Laboratoire de Biologie Cellulaire, URA CNRS 90, UFR Sciences, 40, Avenue du Recteur Pineau, 86022 Poitiers Cédex, France.

Copyright (C) 1989 Society for Neuroscience $0270-6474 / 89 / 061943-08 \$ 02.00 / 0$
One of the signals elaborated by the pineal organ (or pineal) of vertebrates is melatonin. This agent, produced during nighttime, is considered as an internal Zeitgeber, which is involved in the control of nyctohemeral and seasonal rhythms of behavior, of physiological functions, and, more generally, of metabolisms.

In most representatives of different vertebrate classes, melatonin biosynthesis is very low during daytime and high during nighttime. The nocturnal rise results from an increase in activity of the arylalkylamine- $N$-acetyltransferase (NAT), an enzyme that converts serotonin (5-HT) to $\mathrm{N}$-acetylserotonin (Klein et al., 1981). Most authors believe that the hydroxyindole- $O$ methyltransferase, which converts the acetylated 5-HT into melatonin, does not display significant daily changes in activity, at least in endotherms and teleost fish (Falcón et al., 1987, and references therein). The photoperiodic information appears as an important environmental factor controlling the daily rhythm of melatonin production (reviewed by Collin et al., 1987).

From studies in some representatives of teleosts, sauropsids, and mammals, it has been proposed that the pineal chief cells (or transducers) are responsible for indole metabolism, involving melatonin biosynthesis (Falcón and Collin, 1985; Collin et al., 1986a, b; McNulty, 1986; Voisin et al., 1988). The pineal of vertebrates displays a unique evolution of its chief cells (Collin, 1971; Collin and Oksche, 1981; Collin et al., 1986a). In lower vertebrates, most pineal transducers are represented by typical photoreceptors, structurally analogous to retinal cones. During the course of evolution, they are gradually replaced by modified photoreceptors (mainly found in reptiles and birds) and then by pinealocytes stricto sensu (mainly found in mammals). To these stages of differentiation of the pineal transducers corresponds a plurality of mechanisms involved in the photoperiodic control of signal production (including melatonin) by the pineal of vertebrates (Collin et al., 1988, and unpublished observations). Such mechanisms have been most recently studied in the mammalian pinealocytes. Our knowledge on the matter is relatively restricted for the modified photoreceptors and practically nonexistent for the typical photoreceptors.

During the last decade, we gathered some data on the pineal of a teleost fish, the pike (see references in Falcón et al., 1987). At the cellular level, this fish appeared to be a suitable model for investigating the regulatory mechanisms of melatonin synthesis because typical and modified photoreceptors are localized in well-defined pineal regions (Falcón, 1979). However, before the problem of the regulation of melatonin syrithesis by environmental lighting in both types of photoreceptors could be pursued, additional data at the level of the organ was necessary. In the present work we complete a recent in vivo physiological 
Table 1. Experimental conditions

\begin{tabular}{|c|c|c|c|c|}
\hline $\begin{array}{l}\text { Ex- } \\
\text { peri- } \\
\text { ment }\end{array}$ & $\begin{array}{l}\text { Pike weight } \\
\text { (gm) }\end{array}$ & Time of year & $\begin{array}{l}\text { Photoperiod and tem- } \\
\text { perature before death }\end{array}$ & $\begin{array}{l}\text { Type of experimental photo- } \\
\text { period and temperature }\end{array}$ \\
\hline $1 \mathrm{a}$ & $500-700$ & early November & $\begin{array}{l}12 \mathrm{~L}(0700-1900) / \\
12 \mathrm{D}, 12^{\circ} \mathrm{C}\end{array}$ & $\begin{array}{l}\text { Static organ culture, } L D \text { as before, } \\
\text { death }\left(25^{\circ} \mathrm{C}\right)\end{array}$ \\
\hline $1 b$ & $500-700$ & early November & $\begin{array}{l}12 \mathrm{~L}(0700-1900) / \\
12 \mathrm{D}, 12^{\circ} \mathrm{C}\end{array}$ & Static organ culture, $\operatorname{LL}\left(25^{\circ} \mathrm{C}\right)$ \\
\hline 2 & $500-700$ & end of November & $\begin{array}{l}10 \mathrm{~L}(0800-1800) / \\
14 \mathrm{D}, 12^{\circ} \mathrm{C}\end{array}$ & Static organ culture, $\mathrm{DD}\left(27^{\circ} \mathrm{C}\right)$ \\
\hline 3 & 300 & March & $\begin{array}{l}12 \mathrm{~L}(0700-1900) / \\
12 \mathrm{D}, 12^{\circ} \mathrm{C}\end{array}$ & $\begin{array}{l}\text { Static organ culture, lights off } \\
1900, \text { lights on } 0100,\left(25^{\circ} \mathrm{C}\right)\end{array}$ \\
\hline 4 & 200 & early July & $\begin{array}{l}16 \mathrm{~L}(0600-2200) / 8 \mathrm{D} \\
25^{\circ} \mathrm{C}\end{array}$ & $\begin{array}{l}\text { Superfusion, LD and temperature } \\
\text { as before death }\end{array}$ \\
\hline 5 & \multicolumn{3}{|c|}{ Same as in experiment 2} & Superfusion, DD $\left(27^{\circ} \mathrm{C}\right)$ \\
\hline 6 & 250 & mid-November & $\begin{array}{l}10 \mathrm{~L}(0800-1800) / \\
14 \mathrm{D}, 12^{\circ} \mathrm{C}\end{array}$ & $\begin{array}{l}\text { Superfusion, lights off } 1200 \text {, lights } \\
\text { on } 0300,\left(25^{\circ} \mathrm{C}\right)\end{array}$ \\
\hline $7^{a}$ & $250-500$ & early February & $\begin{array}{l}10,5 \mathrm{~L}(0800-1830) / \\
13,5 \mathrm{D}, 12^{\circ} \mathrm{C}\end{array}$ & $\begin{array}{l}\text { Death and blood collection every } \\
3 \mathrm{hr}\end{array}$ \\
\hline
\end{tabular}

LD, light/dark schedule; LL, continuous light; DD, continuous darkness.

"Animals used in experiment 7 were the same as those used to determine pineal melatonin content in experiment 1 of Falcón et al. (1987).

investigation (Falcón et al., 1987) by an in vitro study focused on the role of different lighting conditions on melatonin secretion. In addition, data obtained on fish pineal might increase our knowledge of the retina. Indeed, recent data favor the view that retinal photoreceptors are also involved in the production of 5-methoxyindoles, e.g., melatonin(Wiechmann, 1986; Voisin et al., unpublished observations).

\section{Materials and Methods}

\section{Animals}

Pike (Esox lucius, L.; teleost fish), originating from ponds of the PoitouCharentes region, were collected in a commercial hatchery. In the hatchery they were stored in small ponds, supplied with river water, and submitted to natural conditions of water temperature and photoperiod. In the laboratory, they were maintained for $1-7 \mathrm{~d}$ in oxygenated pond or tap water under conditions of photoperiod and temperature (Table 1) as close as possible to natural ones.

\section{Dissection}

Animals were killed by decapitation approximately $4 \mathrm{hr}$ before the onset of night. A skull cap was removed, and the pineal was quickly detached from the meninges and from the roof of the diencephalon. In most cases, a portion of the dorsal sac was removed together with the pineal. Previous data did not indicate a contribution of the dorsal sac in indole metabolism (Falcón et al., 1987).

In experiment 7 (see below), blood was collected from the bulbus of the aorta, under light when samples were taken during the light phase or under dim red light for dark-phase samples. Blood samples were allowed to clut for $1 \mathrm{hr}$ at room temperature and then overnight at $+4^{\circ} \mathrm{C}$. After a $30 \mathrm{~min}$ centrifugation at $2500 \times g\left(+4^{\circ} \mathrm{C}\right)$, the pellet was discarded and the supernatant (serum) was stored at $-30^{\circ} \mathrm{C}$ until the melatonin radioimmunoassay.

\section{Static organ culture and NAT assay}

After dissection, each pineal was placed on a piece of Nylon mesh in a 24 well culture plate (Nunc, Strasbourg, France) containing $200 \mu \mathrm{l} /$ well of Dubelcco's modified Eagle's medium (DMEM, Gibco, Grand Island, NY) supplemented with BSA (Sigma, $1 \mathrm{mg} / \mathrm{ml}$ ), penicillin, and streptomycin (Gibco, $100 \mathrm{U} / \mathrm{ml}$ and $100 \mu \mathrm{g} / \mathrm{ml}$, respectively), glutamine (Gibco, $2 \mathrm{~mm})$, and ascorbic acid $(0.1 \mathrm{mg} / \mathrm{ml})$. The plates were placed in an incubation chamber supplied with a mixture of $\mathrm{O}_{2} / \mathrm{CO}_{2}(19: 1)$. In the incubator, light was provided by a fluorescent lamp (30 W) giving a 1000 lux illumination intensity at the dishes. Pineals were transfered to fresh medium each $12 \mathrm{hr}$. Cultures were run at 25 or $27^{\circ} \mathrm{C}$ (see Table 1). Previous studies have shown that temperatures up to $30^{\circ} \mathrm{C}$ are suitable for culturing organs from freshwater teleosts (Wolf and Quimby, 1969; McNulty, 1984). Organ culture was followed by immediate freezing of the pineals in liquid nitrogen, until NAT assay. The enzymatic assay for pike pineals has already been described in detail elsewhere (Falcón et al., 1987). Briefly, the organs were sonicated in $100 \mu \mathrm{l}$ sodium phosphate buffer $(0.1 \mathrm{M}, \mathrm{pH} 6.8)$ at $+4^{\circ} \mathrm{C}$. A $50 \mu \mathrm{l}$ aliquot of the homogenate was added to $50 \mu \mathrm{l}$ sodium phosphate buffer containing 20 $\mathrm{mmol} /$ liter tryptamine (Sigma) and $1 \mathrm{mmol} /$ liter ${ }^{3} \mathrm{H}$-acetylcoenzyme A (New England Nuclear; final specific activity, $4 \mathrm{mCi} / \mathrm{mmol}$ ). The reaction was carried out for $1 \mathrm{hr}$ at $25^{\circ} \mathrm{C}$ in a water bath and stopped by addition of $1 \mathrm{ml}$ of chloroform at $+4^{\circ} \mathrm{C}$. The ${ }^{3} \mathrm{H}-N$-acetyltryptamine produced was extracted into the chloroform. After removal of the aqueous phase, the chloroform was washed once with phosphate buffer. The organic phase was then evaporated in scintillation counting vials, and $10 \mathrm{ml}$ of organic counting scintillant (Amersham) was added. Radioactivity was counted in an LKB rack $\beta$ liquid scintillation counter, with a $45 \pm 5 \%$ counting efficiency.

\section{Flow-through organ culture (superfusion)}

The perifusion apparatus was as described by Tonon et al. (1980) with modifications. After dissection, 1-3 pineals were placed on a piece of Nylon mesh ( $1 \mathrm{~cm}$ diameter) in the perifusion chamber. The chamber was composed of a glass tube $(0.9 \times 15 \mathrm{~cm})$ with 2 Teflon plungers. The volume delimited by the plungers $(200-400 \mu \mathrm{l})$ was filled with supplemented culture medium (DMEM, see above). Culture medium was supplied from the upper plunger by means of a peristaltic pump which maintained a flow rate of 500 or $1000 \mu \mathrm{l} / \mathrm{hr}$. The catheter of the lower plunger was connected to an automatic fraction collector. The perifusion culture medium was presaturated with sterilized $95 \% \mathrm{O}_{2} / 5 \%$ $\mathrm{CO}_{2}$ mixture and kept under this gas mixture during the entire run. The temperature (see above and Table l) was controlled by a water bath and by a water flow circulating in a jacket around the chamber. The collected fractions were stored at $-40^{\circ} \mathrm{C}$ until time of melatonin radioimmunoassay.

\section{Melatonin radioimmunoassay}

From plasma. The melatonin content of $500 \mu \mathrm{l}$ of plasma sample was extracted by $3 \mathrm{ml}$ chloroform. Briefly, the organic phase was evaporated under vacuum after a 30 min centrifugation at $3500 \times g\left(\right.$ at $\left.+4^{\circ} \mathrm{C}\right)$. Melatonin was resuspended in buffer (Eurodiagnostics BV kit) and fro- 


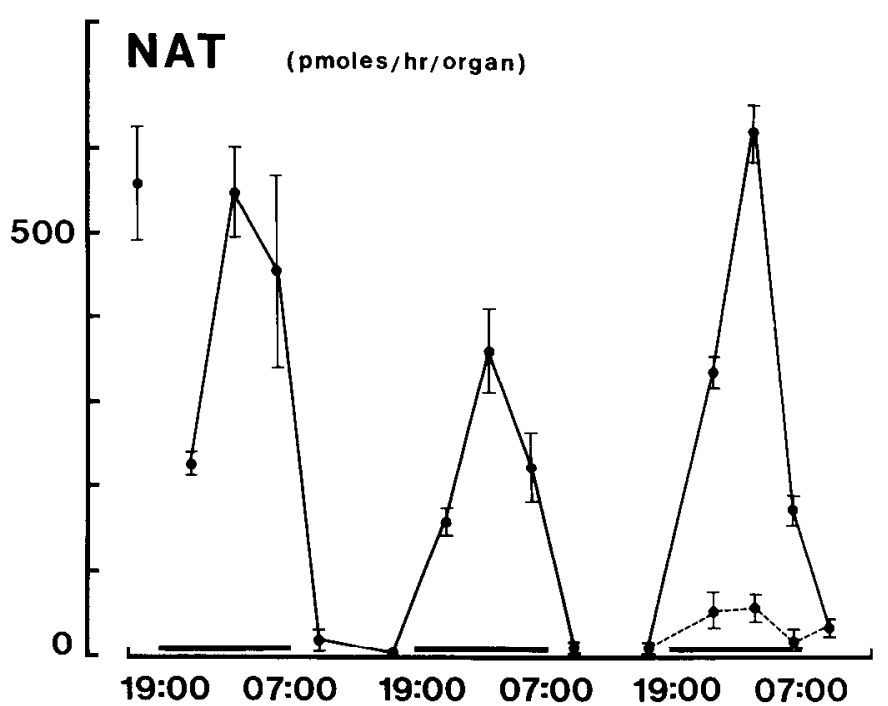

Figure 1. Variations of the NAT activity of cultured pike pineals maintained under a $\mathrm{LD}(\mathrm{L}=1000 \mathrm{lux}$ ) (solid line) or under a LL (interrupted line) schedule. Thick har on the abscissa indicates scotophase. The first value on the top left is that of NAT activity just after death $(n=3$; mean $\pm \mathrm{SEM} ; F=36.8, p<0.001$ for the $3 \mathrm{LD}$ cycles; $F=3.45, p<$ 0.05 for the LL cycle; studentized multiple-range test).

zen at $-30^{\circ} \mathrm{C}$ if not assayed immediately. The radioimmunoassay, which uses ${ }^{125}$ I-melatonin as a tracer, was run (in duplicates for each sample) as described in the protocol of the commercially available kit used (Eurodiagnostics, BV, Amsterdam). Counts were performed with an LKB mini $\gamma$ spline counter (counting efficiency, $70 \%$ ).

From pineal perfusates. Melatonin levels in the pineal perfusates were determined in duplicate by using the radioimmunoassay developed by Brun and Claustrat (Brun et al., 1985), without extraction of the samples. Appropriate volumes of pineal perfusates were diluted 50,1000 , or 10,000 times with assay buffer to a total volume of $300 \mu \mathrm{l}$. Then, 100 $\mu{ }^{125} \mathrm{I}$-melatonin analog $(20,000 \mathrm{cpm}$, in assay buffer $)$ and $100 \mu \mathrm{l}$ antiserum (1:80,000 in assay buffer) were added to the diluted pineal perfusate (final antiserum dilution, 1:400,000). The reaction mixture was incubated overnight at $+4^{\circ} \mathrm{C}$, after which $1 \mathrm{ml}$ anti-rabbit sheep gamma globulin (INRA, Nouzilly, France) was added to each tube. After a 30 min incubation at room temperature, followed by $30 \mathrm{~min}$ centrifugation $\left(3500 \times g,+4^{\circ} \mathrm{C}\right)$, the supernatant was decanted and the radioactivity was measured in the precipitate (Kontron gamma matic or LKB mini gamma).

\section{Validation}

Radioimmunoassay of pineal perfusates. The high sensitivity and specificity of the antiserum used has been described extensively elsewhere (Brun et al., 1985).

Maximal binding was not modified by using 1:50 diluted (in assay buffer) or undiluted culture medium. Standard curves obtained with 1:50 diluted culture medium were identical to those obtained with assay buffer, thereby showing that there were no interfering substances in the culture medium. The lower and upper limits of the assay were 1.5 and $800 \mathrm{pg} / \mathrm{tubc}$, respectivcly, and $50 \%$ inhibition was usually produced upon addition of $13 \pm 1 \mathrm{pg} /$ tube of melatonin. When pooled nocturnal pineal perfusates (averaged concentration: $11.8 \mathrm{ng} / \mathrm{ml}$ ) were diluted in assay buffer ( 5 dilutions corresponding to $353.4,176.7,70.7,35.3$, and $17.7 \mathrm{pg} /$ tube, respectively), the expected melatonin concentrations were recovered $\pm 5 \%$. When tubes of pooled diurnal $(3.4 \mathrm{pg} /$ tube $)$ and pooled nocturnal (45 pg/tube) pineal perfusates (diluted 1:50 in assay buffer) received 50,100 , or $200 \mathrm{pg}$ melatonin, the respective percentages of recovery were $100.2,111.2$, and 110.6 (diurnal perfusate) and 82.1, 96.5 , and 114.3 (nocturnal perfusate). Pooled pineal perfusates (1:50 in assay buffer) giving $49.6 \mathrm{pg} /$ tube of melatonin had an intra-assay coefficient of variation of $10 \%$ ( 9 replicates). The respective interassay coefficient of variation was $12 \%$ (4 assays).

The values obtained in the present validation were within the range

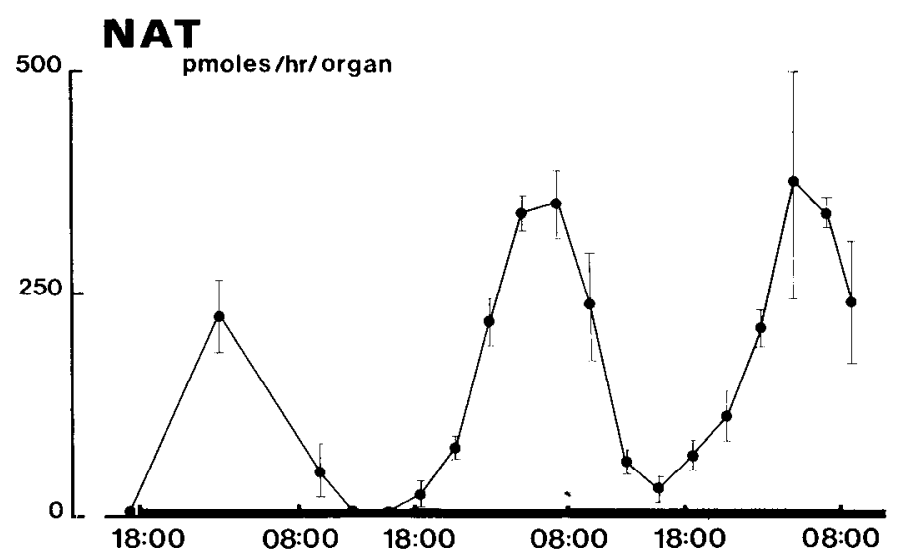

Figure 2. Variations of the NAT activity of cultured pike pineals maintained under DD during three $24 \mathrm{hr}$ cycles: subjective photophases from 0800 to $1800(n=3$; mean $\pm \mathrm{SEM} ; F=5.63, p<0.001$; studentized multiple-range test).

of those obtained after diethylether melatonin extraction from mammalian pineals and from human serum and urines (Brun et al., 1985).

Radioimmunoassay of extracted serum samples. The radioimmunoassay has not yet been validated for chloroform-extracted serum samples of pike. In the study reported here, we were primarily concerned with rhythmicity phenomena rather than with biochemical details. However, the reader should bear in mind that serum "melatonin" is used as an abbreviation for "radioimmunoassayable melatonin." (A validation has been done for diethylether-extracted human serum; Eurodiagnostics BV.)

NAT assay. Under our experimental conditions, the assay is linear with time and with amount of pineal tissue (unpublished data).

\section{Statistics}

Values were compared using the studentized multiple range ( $F$ of Snedecor) test or the Student $t$ test (Bliss, 1967).

\section{Experimental conditions}

Experimental conditions are summarized in Table 1 (see also figures and legends).

\section{Results}

Experiment la: NAT activity in pineals under the LD schedule Significant $(F=36.8, p<0.001)$ day/night differences in NAT activity were detected under our experimental conditions. NAT activity was between $0-36 \mathrm{pmol} / \mathrm{hr} /$ organ during the light phase and reached 226-624 pmol/hr/organ during the dark phase. The activity increased dramatically shortly after the lights went off and decreased before the end of the scotophase, during three 24 hr LD cycles. Peak activity was at 02:00. The maximal nocturnal NAT activity in culture did not exceed daytime values measured just after death (Fig. 1).

\section{Experiment 1b: NAT activity in pineals under the LL schedule} Under continuous illumination, 1 cycle of 24 hr (Fig. 1, right), NAT activity was very low during the subjective scotophase compared with its activity during the scotophase of the LD experiment $(54.2,63.5$, and $18 \mathrm{pmol} / \mathrm{hr} /$ organ, respectively, versus $338.4,623.9$, and $175.4 \mathrm{pmol} / \mathrm{hr} / \mathrm{organ})$. Nevertheless, these values were still significantly higher than those detected during the subjective light phase $(F=3.45, p<0.05)$.

\section{Experiment 2: NAT activity in pineals under a DD schedule}

Under conditions of constant darkness, NAT activity continued to oscillate significantly $(F=5.63, p<0.001)$ during at least 


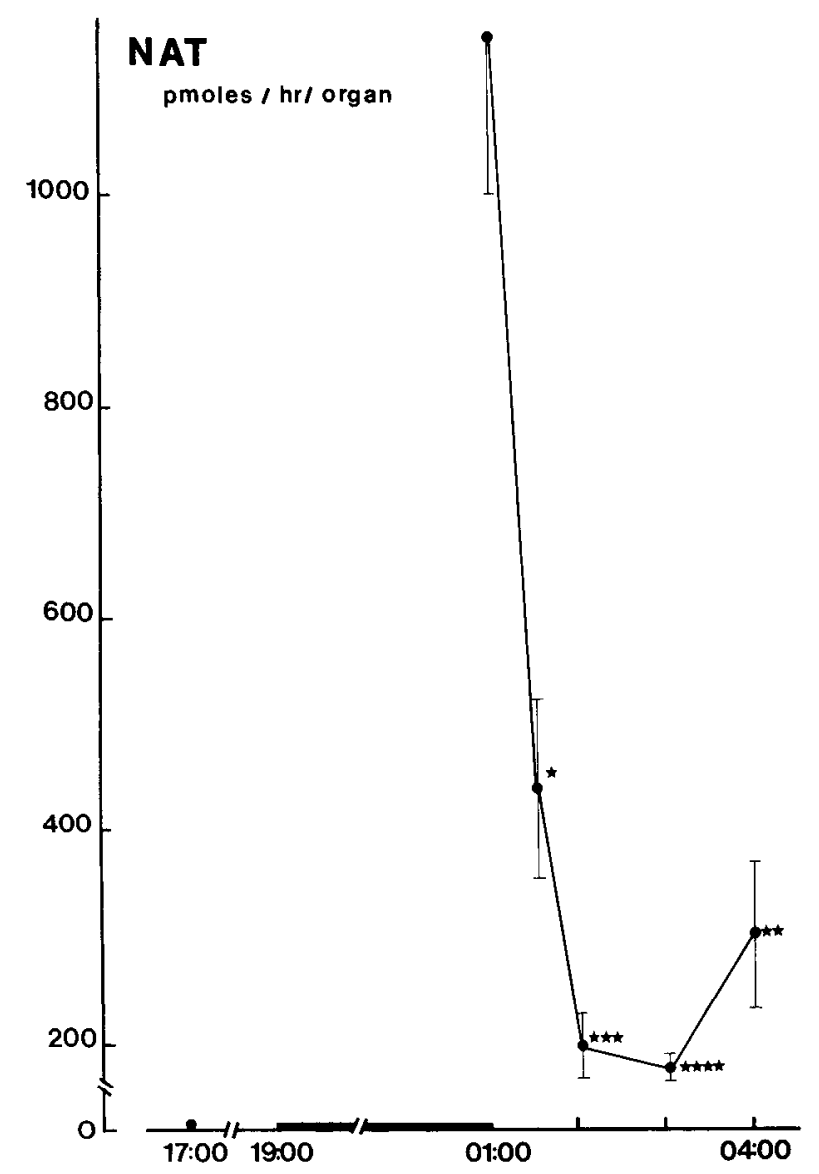

Figure 3. Effect of illumination (1000 lux) at midscotophase, on nocturnal NAT activity of cultured pike pineals. Basal daytime values were measured at 1700 . Lights went off at 1900 , and maximal activity was measured $5 \mathrm{~min}$ before illumination at $0100[n=4$; mean \pm SEM; values compared with the nocturnal peak by the Student $t$ test gave $\star p$ $<0.005, \star \star p<0.002, \star \star \star p<0.001, \star \star \star \star p<0.0005$; analysis of variance gave $F=18.45,(p<0.001)$, and means were compared with the nocturnal peak, giving $p<0.05(\star)$ and $p<0.01(\star \star$ or more)].

three $24 \mathrm{hr}$ cycles (Fig. 2). The increase of NAT activity was very progressive after the onset of the subjective scotophase of the second and third cycles, respectively; maximal activity was reached only during the last $4 \mathrm{hr}$ of these phases. At the beginning of the second and third subjective light phases, NAT activity was high compared with the corresponding value of the first subjective light phase.

\section{Experiment 3: effect of illumination on nocturnal NAT activity}

Illumination (1000 lux) at midscotophase of cultured organs resulted in a rapid but incomplete inactivation of NAT (Fig. 3). After $1 \mathrm{hr}$ of illumination, about $83 \%$ of the initial activity (measured $5 \mathrm{~min}$ before the lights went on) was lost. Half-inactivation was reached at approximately $20 \mathrm{~min}$. NAT activity was maintained at $17 \%$ of the nocturnal value after $2 \mathrm{hr}$ of light. A slight $(+10 \%)$, but not significant, increase was observed after $3 \mathrm{hr}$.

Experiment 4: melatonin release by superfused pineals under the $L D$ schedule

Individual superfused pineals released melatonin rhythmically in the perfusate, during the two $24 \mathrm{hr} \mathrm{LD}$ cycles investigated.
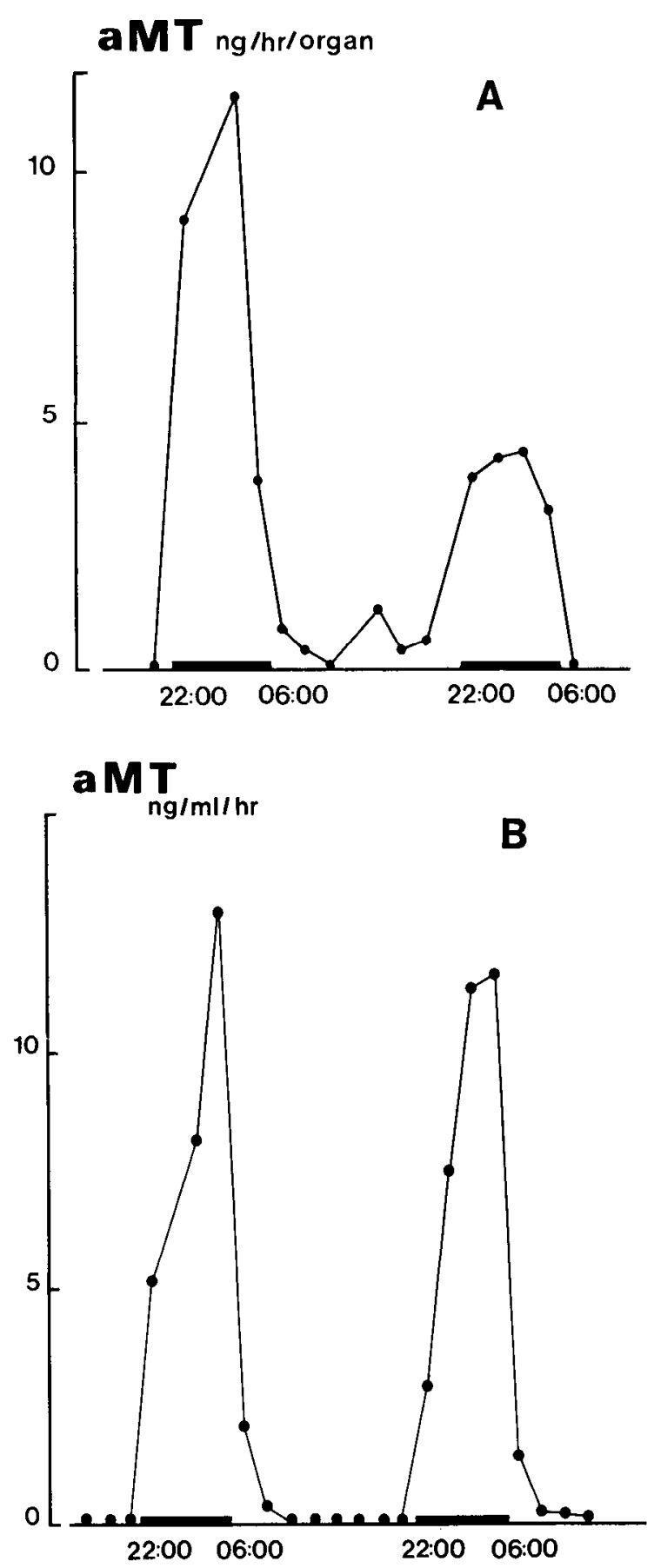

Figure 4. Rhythms of melatonin release during a LD cycle. One $(A)$ and three $(B)$ pike pineals are cultured in a flow-through superfusion system $(L=1000$ lux intensity; $b a r=$ scotophase). Samples of perfusates were collected for $1 \mathrm{hr}$ (flow rate, $500 \mu \mathrm{l} / \mathrm{hr}$ ). Each point represents a duplicate determination and is plotted at the start of the collection interval.

Melatonin concentrations in the perfusates were high during nighttime and low during daytime (Fig. $4 A$ ). Peak values were reached at midscotophase. Similar results were obtained when 3 pineals were cultured together in one chamber (Fig. $4 B$ ).

Experiment 5: melatonin release by superfused pineals under the $D D$ schedule

Individual superfused pineals, maintained in constant darkness, released melatonin rhythmically for at least three $24 \mathrm{hr}$ cycles 
(Fig. 5). The amplitude of the rhythm was apparently maintained during the 3 cycles. Furthermore, the rhythm displayed a phase shift: the maximal release of melatonin occurred successively at 0300 (first cycle), 0500 (second cycle) and 0700 (third cycle). Moreover, although not based on statistical analysis, there was apparently a linear increase of the mesor from the first to the third cycle.

\section{Experiment 6: effect of darkness at midphotophase and of light at midscotophase on melatonin release by superfused pineals}

Pineals were superfused ( 2 or 3 /incubation chamber) for $24 \mathrm{hr}$ in LD conditions (Table 1). During the following $24 \mathrm{hr}$ cycle, darkness occurred at 1200 (Fig. 6, A, B) and light at 0300 (Fig. $6 B)$. Under these conditions, melatonin release was low from 1200 to 1800 and increased after 1800 , reaching peak values between 2200 and 0200 (Fig. 6, A, B). One hour after turning the lights on (approximately $1000 \mathrm{lux}$ ), melatonin production resumed basal values (Fig. $6 B$ ), i.e., light induced a $92 \%$ decrease in melatonin release.

\section{Experiment 7: nyctohemeral variations of melatonin content in the plasma of pikes under a LD schedule}

The melatonin content of plasma collected during daytime was low-between 70 and $120 \mathrm{pg} / \mathrm{ml}$ (Fig. 7). It was approximately twice that in samples collected during darkness (between 170 and $210 \mathrm{pg} / \mathrm{ml} ; F=4.14, p<0.01$ ).

\section{Discussion}

The present study has provided important new insight into the photoperiodic control of the biosynthesis and release of melatonin, in the pineal of the pike, which is a typical directly photoreceptive organ (Falcón and Meissl, 1981). Most investigations dealing with this matter have used the rat and chicken (see references in Menaker and Binkley, 1981; Klein, 1985; Zatz et al., 1988), where the anatomy, organization of chief cells, and innervation differ considerably from that of anamniotes, such as the pike. As previously stated, the present physiological data are preliminary to a study, at the photoreceptor level, of the molecular mechanisms involved in the translation of the photoperiodic information into a melatoninergic signal.

\section{Entrainment of the NAT activity and melatonin release by the LD cycle}

We have demonstrated that cultured pineals of an anamniote are capable of maintaining nyctohemeral variations in NAT activity under a LD cycle. In vivo pineal NAT activity and melatonin content were synchronized to the LD cycle. Both chronograms closely match each other, with high values being detected during nighttime and low values during daytime (Falcón et al., 1987). The cyclic variations of NAT activity observed in static organ culture were similar to those described in vivo, hence supporting evidence that photoperiodic control of the enzymatic activity results, at least in part, from the direct photosensitivity of the organ in the pike. Because the overall NAT levels in culture were much lower than when measured in vivo, it is suggested that a factor or factors present in vivo and necessary to maintenance of high NAT levels are lacking in culture.

Superfused individual or pooled pineals of pikes also released melatonin in higher amounts during nighttime than during daytime. The pike is the first ectotherm showing that this release reflects pineal rhythms of both NAT activity and melatonin content (see also Falcón et al., 1987).

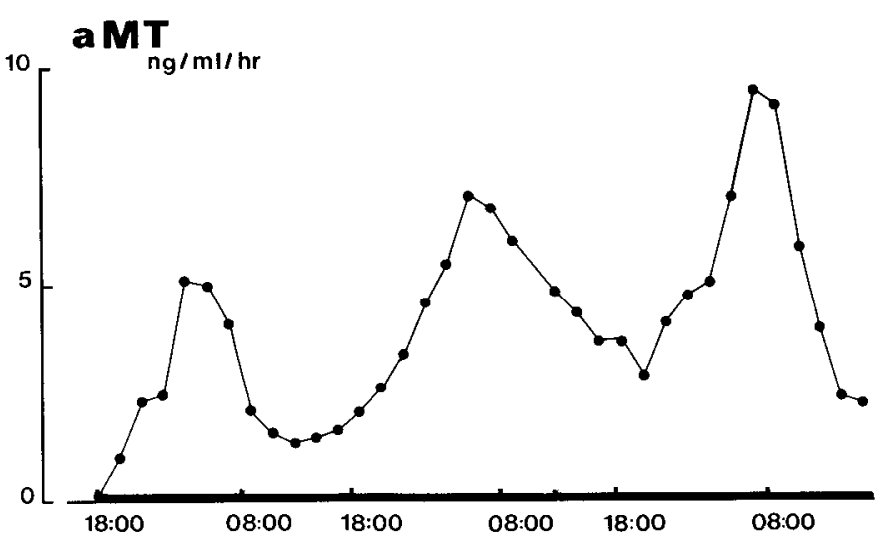

Figure 5. Rhythm of melatonin release by a superfused pike pineal under constant darkness. Flow rate was $1 \mathrm{ml} / \mathrm{hr}$ (subjective photophases from 0800 to 1800 ). Each point represents a duplicate determination ( $1 \mathrm{hr}$ collection) and is plotted at the start of the collection interval.

It is not yet possible to state precisely the extent to which melatonin, released by the pike pineal, contributes to the circulating levels. Indeed, plasma melatonin levels (from samples collected every $3 \mathrm{hr}$; Fig. 7) were high during the scotophase and low during the photophase. However, the retina of vertebrates is known to be a potential source of circulating melatonin (see references in Gern and Karn, 1983). The retina of the pike synthesizes and stores melatonin rhythmically, but superfused retinas did not appear to release significant amounts of melatonin (unpublished observations). It is presently not possible to assert that the situation observed in culture reflects exactly that occurring in vivo. Thus, it is only suggested that, in the pike, the pineal might contribute maximally to the circulating levels of melatonin.

\section{Effects of different lighting conditions on NAT activity and melatonin release}

After pineal NAT activity had been allowed to increase, unexpected dark to light transition at midscotophase, resulted in a decrease in enzyme activity. A similar phenomenon has already been described in the pineal of rats in vivo (Binkley, 1983), chicken in vivo and in culture (Wainwright and Wainwright, 1981, and references therein; Hamm et al., 1983) and pike in vivo (Falcón et al., 1987). In parallel, light given at middark rapidly decreased melatonin release by pike pineal. In contrast to NAT activity, the levels of which remained high compared with those measured during daytime, melatonin release dropped to basal levels after $1 \mathrm{hr}$ of illumination (of identical intensity). We cannot explain these discrepancies. According to Wainwright and Wainwright (1981), the incomplete inactivation of NAT by middark exposure to light may, in the chicken, reflect the existence of a photolabile and a photostable enzymatic pool.

In the present study, the decrease of NAT activity appeared without detectable latency. This is in agreement with what is known to occur in chicken and rat (see references above) but contrasts with the previous results obtained in vivo in the pike, in which a period of latency of more than $10 \mathrm{~min}$ was observed before NAT started to decrease (Falcón et al., 1987). Moreover, (1) half-inactivation was reached after $30 \mathrm{~min}$ of light $(20 \mathrm{~min}$ in culture) and (2) $60 \%$ of the initial nocturnal activity was lost (instead of $80 \%$ in culture). In the pike, these discrepancies may result merely from the use of distinct experimental procedures 

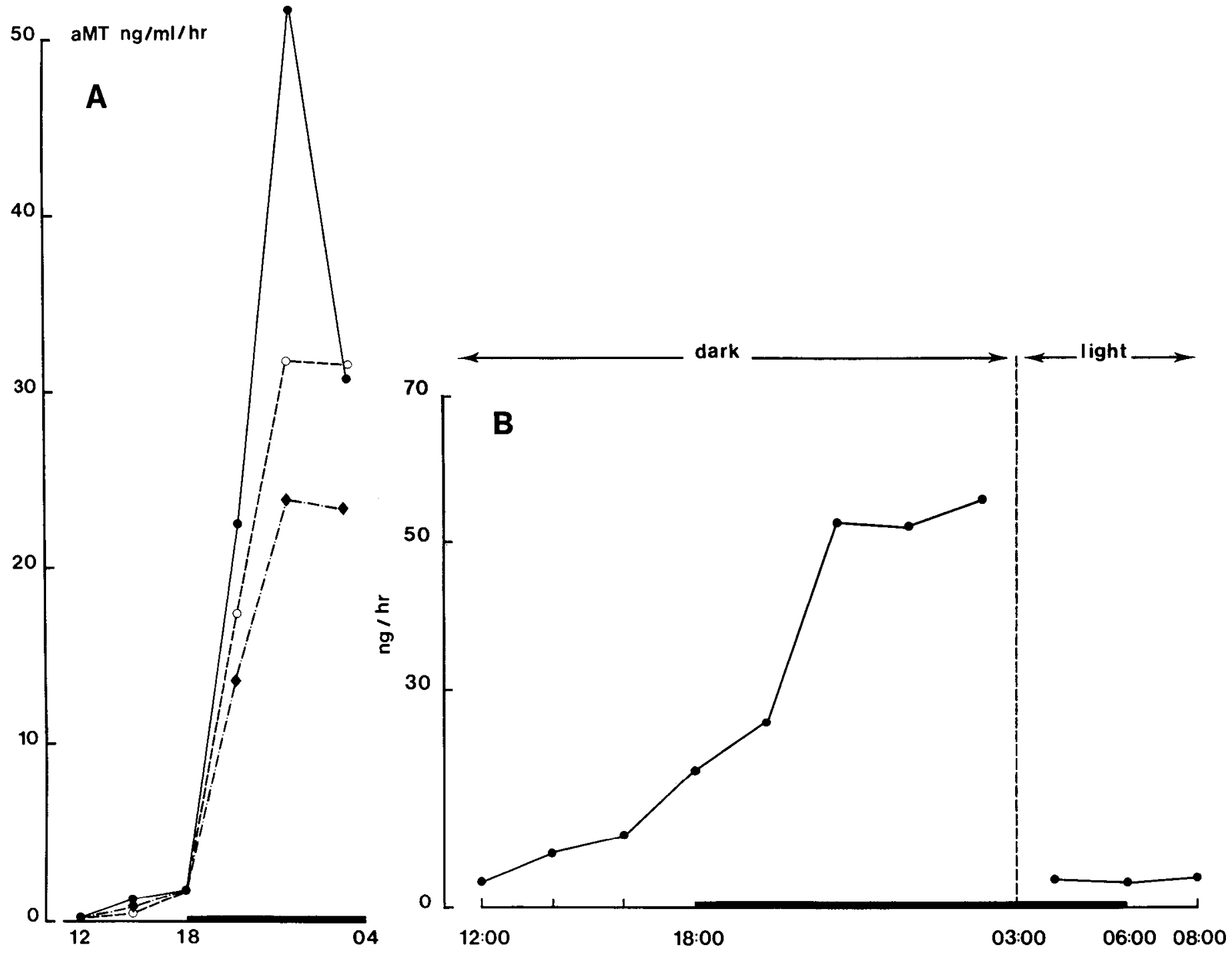

Figure 6. Effect of advancing scotophase on melatonin release by superfused pike pineals. Each point represents a duplicate determination of 1 $\mathrm{hr}$ of collection and is plotted at the start of the collection interval (flow rate was $1 \mathrm{ml} / \mathrm{hr}$ ). $A$, Darkness from 1200 to 0400 (culture was stopped at 0400). Data from 3 individual experiments with 2 pineals per chamber in each. $B$, Darkness was given from 1200 to 0300 (culture was run up to $0800 ; 3$ pineals in one chamber). Thick bar indicates the subjective scotophase.

(e.g., intensity and spectral composition of the light crossing skin and skullcap might be different from that reaching the culture dishes). Alternatively, these may be involvement of (an) extrapineal endogenous factor(s) in the control of pineal NAT activity, which would act only in vivo, via humoral and/or nervous pathways.

The partial inhibitory effect of light on pineal NAT activity was further evidenced by exposing cultured organs to continuous light (LL) for $24 \mathrm{hr}$. As in in vivo experiments (Falcón et al., 1987), a small but significant rise in activity was detected during the subjective nighttime. This indicates the existence of an endogenous low-amplitude rhythm of NAT activity. It remains to be determined whether this rhythm can be maintained for more than a single $24 \mathrm{hr}$ LL cycle. A rhythm in NAT activity under LL has also been observed in chicken pineal (Wainwright and Wainwright, 1980,1981). The rhythm was of low amplitude and did not persist for more than $24 \mathrm{hr}$ in culture; it was of high amplitude and lasted for at least three $24 \mathrm{hr}$ LL cycles in vivo (Wainwright and Wainwright, 1981) but was no longer apparent after $15 \mathrm{~d}$ (Ralph et al., 1975).

Pike pineals cultured under DD were able to sustain highamplitude oscillations in NAT activity and melatonin release for at least three $24 \mathrm{hr}$ cycles. Moreover, advancing the scotophase at midday did not induce an increase in melatonin release as observed in the trout pineal (W. A. Gern and S. S. Greenhouse, personal communication). Altogether, our data strongly support the view that the rhythm of NAT activity-and consequently that of melatonin release-are driven by an endogenous oscillator in the pineal of the pike. Such an oscillator is circadian because the period of NAT and melatonin oscillations, generated by the pineal itself, approximates $24 \mathrm{hr}$, under constant conditions (Figs. 2, 5). An endogenous circadian oscillator has been evidenced previously in the chicken and in a lizard (Anolis) but not in another lizard or the trout (see review by Menaker, 1985; W. A. Gern, personal communication). In the pineal of the pike, as well as that of chicken and Anolis, the 


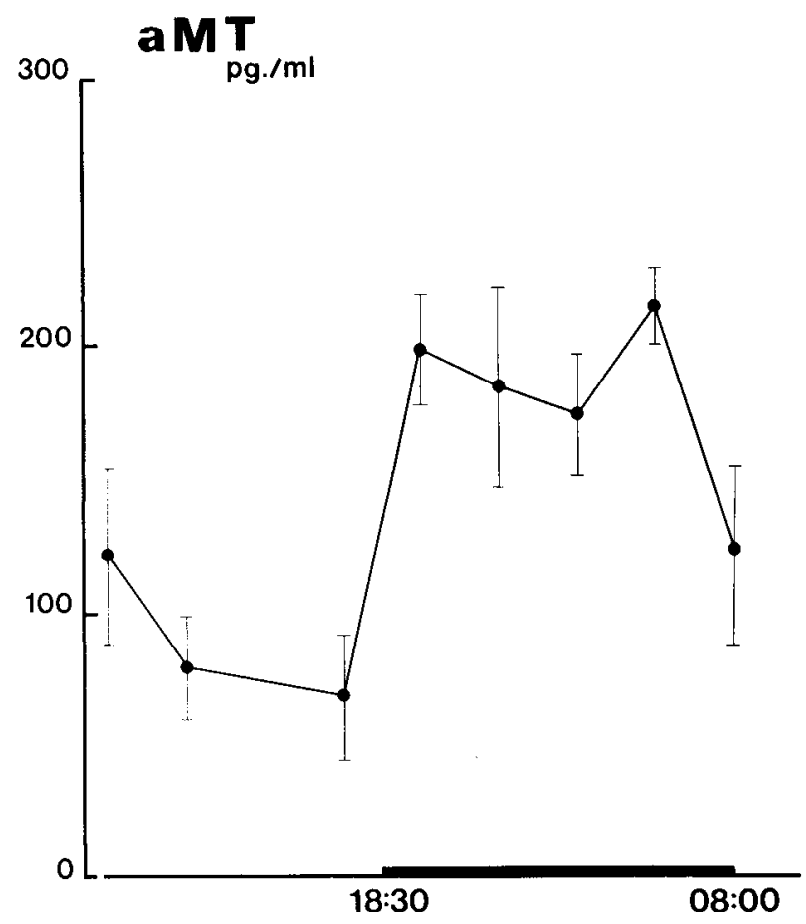

Figure 7. Variations of plasma melatonin content of pikes maintained under a LD cycle [same animals as those used for the determination of pineal melatonin content in Falcón et al. (1987); $n=3$; mean $\pm \mathrm{SEM}$; $F=4.14, p<0.01$ studentized multiple-range test].

free-running rhythms of NAT and melatonin generated by the oscillator are synchronized by alternating $\mathrm{L}$ and $\mathrm{D}$ (photoperiod) during the $24 \mathrm{hr}$ cycle (see Falcón et al., 1987, for the pike).

The chronograms of NAT activity and, to a greater degree, of melatonin release by pike pineal cultured under DD were somewhat different from those described in other vertebrate species investigated. In the chicken, NAT activity and melatonin release are considerably lowered, and their rhythms are rapidly damped before they disappear (see references in Menaker and Binkley, 1981; Zatz et al., 1988). In the trout, there is no endogenous rhythmicity but a continuous release of high amounts of melatonin under DD (Gern and Greenhouse, personal communication). Finally, Menaker and Wisner (1983) reported sustained oscillations in the release of melatonin by superfused pineals of the lizard Anolis for up to 10 cycles. In contrast (see Menaker and Wisner, 1983, figure 1), in the pike (1) the amplitude of the oscillation was apparently maintained during the first 3 cycles and (2) averaged minima and maxima of each of these cycles seemed to increase gradually. Further studies are needed to define these differences precisely. Among the few pineals of vertebrates currently under investigation, that of the pike seems to behave differently, and it might offer new perspectives in the study of the mechanisms of the endogenous oscillations. These differences may result from the stage of differentiation of pineal transducers (see introductory remarks).

Investigations conducted in Anolis (an ectotherm) have shown that temperature also influences melatonin sccretion (Mcnaker and Wisner, 1983; Underwood, 1985). The pineals of the pikes used in the present study were cultured at 25 or $27^{\circ} \mathrm{C}$, temperatures that (1) are suitable for the culture of organs of freshwater teleosts (see Materials and Methods) and (2) correspond to those of the ponds of the Poitou-Charentes region in summer. The temperatures used in the present work allowed the expression of endogenous oscillations (NAT, melatonin) under DD. We have previously described a strong damping of in vivo NAT activity rhythm under DD in pikes previously adapted to winter photoperiod $(10 \mathrm{~L} / 14 \mathrm{D})$ and temperature $\left(+5^{\circ} \mathrm{C}\right)($ Falcón et al., 1987). Our actual investigations tend to increase the present data in favor of the presence of the endogenous oscillator, as well as the role of temperature in its entrainment and its expression.

\section{Conclusions and perspectives}

Both categories of pineal photoreceptor cells in the pike pineal (see introductory remarks) respond directly to light/dark information of the $24 \mathrm{hr}$ cycle and synthesize and store indole compounds, including melatonin (Falcón and Meissl, 1981; Falcón, 1984; Falcon and Collin, 1985, and references therein). The daily oscillations in NAT activity (in vivo and in vitro) and of melatonin content (in vivo) or release (in vitro) correlate well with the daily changes of $\mathrm{N}$-acetylserotonin-like and melatoninlike compounds, evidenced cytochemically (Falcón, 1984; Falcón and Collin, 1985; Falcón et al., 1987, and present work). Altogether, it seems reasonable to propose that both types of pineal photoreceptors are involved in the photoperiodic control of melatonin biosynthesis and release in the pike. It has been suggested that the pineal photoreceptors of vertebrates are components of the circadian system and that they might contain (at least in some species) an oscillator in addition to the photoreceptive unit and to the machinery for melatonin production (Collin et al., 1986a, b). Information is now available concerning (1) the photoperiodic regulation of melatonin biosynthesis and release and (2) the regional distribution and structure/function of both types of photoreceptor cells in the pineal of pike. Undoubtedly, this organ offers interesting perspectives, at the cellular levcl, not only for the localization of the oscillator(s), but also for the study of the mechanisms of the oscillations and its (their) entrainment by exogenous factors. In view of the data discussed here, it appears that the results obtained in this lower vertebrate might permit insights into the physiology of extraretinal and retinal photoreceptor cells.

\section{References}

Binkley, S. (1983) Circadian rhythms of pineal function in rats. Endocrinol. Rev. 4: 225-270.

Bliss, C. I. (1967) Statistics in Biology, McGraw-Hill, New York.

Brun, J., C. Claustrat, C. Harthe, P. A. Vitte, R. Cohen, and M. G. Chazot (1985) Melatonin radioimmunoassay. Analytical and physiological criteria of validity. Adv. Biosci. 53: 41-45.

Collin, J. P. (1971) Differentiation and regression of the cells of the sensory line in the epiphysis cerebri. In The Pineal Gland: $A$ Ciba Foundation Symposium, G. E. W. Wolstenholme and J. Knight, eds., pp. 79-125, Churchill Livingstone, Edinburgh.

Collin, J. P., and A. Oksche (1981) Structural and functional relationships in the non mammalian pineal gland. In The Pineal Gland, Vol. 1, Anatomy and Biochemistry, R. J. Reiter, ed., pp. 27-67, CRC, Boca Raton, FL.

Cullin, J. P., P. Brisson, J. Falcón, and P. Voisin (1986a) Multiple cell types in the pineal: Functional aspects. In Pineal and Retinal Relationships, P. J. O’Brien and D. C. Klein, eds., pp. 15-32, Academic, New York.

Collin, J. P., H. Meissl, P. Voisin, P. Brisson, and J. Falcón (1986b) Rhythmic signals of pineal transducers: Physiological, biochemical and cytochemical evidence. In Advances in Pineal Research, Vol. I, R. J. Reiter and M. Karasek, eds., pp. 41-50, J. Libbey, London.

Collin, J. P., P. Voisin, J. Falcón, and P. Brisson (1987) Evolution and environmental control of secretory processes in pineal transducers. In Functional Morphology of Neuroendocrine Systems, B. 
Scharrer, H. W. Korf, and H. G. Hartwig, eds., pp. 105-119, SpringerVerlag, Berlin.

Collin, J. P., J. P. Faure, J. Falcón, P. Voisin, P. Brisson, and M. Mirshahi (1988) Pinéale et rétine. Médecine/sciences 4:16-26.

Falcón, J. (1979) L'organe pinéal du Brochet (Esox lucius, L.). II. Etude en microscopie électronique de la différenciation et de la rudimentation partielle des photorécepteurs; conséquences possibles sur l'élaboration des messages photosensoriels. Ann. Biol. Anim. Biochim. Biophys. 19: 661-688.

Falcón, J. (1984) Photosensitivity and biosynthesis of indole compounds in the cells of the receptor line of the pineal organ of the pike. Ophthalmic Res. 16: 123-128.

Falcón, J., and J. P. Collin (1985) In vitro uptake and metabolism of $\left[{ }^{3} \mathrm{H}\right]$-indole compounds in the pineal organ of the pike. II. A radioautographic study. J. Pineal Res. 2: 357-373.

Falcón, J., and H. Meissl (1981) The photosensory function of the pineal organ of the pike (Esox lucius, L.). Correlation between structure and function. J. Comp. Physiol. 144: 127-137.

Falcón, J., J. F. Guerlotté, P. Voisin, and J. P. Collin (1987) Rhythmic melatonin biosynthesis in a photoreceptive pineal organ: A study in the pike. Neuroendocrinology 45: 479-486.

Gern, W. A., and C. M. Karn (1983) Evolution of melatonin's functions and effects. Pineal Res. Rev. 1: 49-90.

Hamm, H. E., J. S. Takahashi, and M. Menaker (1983) Light-induced decrease of serotonin $\mathrm{N}$-acetyltransferase activity and melatonin in the chicken pineal gland and retina. Brain Res. 266: 287-293.

Klein, D. C. (1985) Photoregulation of the mammalian pineal gland. In Ciba Foundation Symposium 117: Photoperiodism, Melatonin and the Pineal, D. Evered and S. Clark, eds., pp. 38-56, Pitman, London.

Klein, D. C., D. A. Auerbach, M. A. A. Namboodiri, and G. H. T. Wheler (1981) Indole metabolism in the mammalian pineal gland. In The Pineal Gland, Vol. 1: Anatomy and Biochemistry, R. J. Reiter, ed., pp. 199-227, CRC, Boca Raton, FL.

McNulty, J. A. (1984) Organ culture of the goldfish pineal body. An ultrastructural and biochemical study. Cell Tissue Res. 238: 565-575.

McNulty, J. A. (1986) Uptake and metabolism of indole compounds by the goldfish pineal organ. Gen. Comp. Endocrinol. 61: 179-186.

Menaker, M. (1985) Eyes - the second (and third) pineal glands? In Ciba Foundation Symposium 117: Photoperiodism, Melatonin and the Pineal, D. Evered and S. Clark, cds., pp. 78-92, Pitman, London.
Menaker, M., and S. A. Binkley (1981) Neural and endocrine control of circadian rhythms in the vertebrates. In Handbook of Behavioral Neurobiology, Vol. 4, Biological Rhythms, J. Aschoff, ed., pp. 243255 , Plenum, New York.

Menaker, M., and S. Wisner (1983) Temperature-compensated circadian clock in the pineal of Anolis. Proc. Natl. Acad. Sci. USA 80. 6119-6121.

Ralph, C. L., S. Binkley, S. E. MacBride, and D. C. Klein (1975) Regulation of pineal rhythms in chickens: Effects of blinding, constant light, constant dark, and superior cervical ganglionectomy. Endocrinology 97: 1373-1378.

Tonon, M. C., Г. Leboulanger, C. Delarue, S. Jegou, J. Frescl, P. Lcroux, and H. Vaudry (1980) TRH as MSH-releasing factor in the frog. In Biochemical Endocrinology: Synthesis and Release of Adenohypophysial Hormones, Cellular and Molecular Mechanisms, M. Jutisz and K. W. McKerns, eds., pp. 731-751, Plenum, New York.

Underwood, H. (1985) Pineal melatonin rhythms in the lizard Anolis carolinensis: Effects of light and temperature cycles. J. Comp. Physiol. A 157: 57-65.

Voisin, P., J. Guerlotté, and J. P. Collin (1988) An antiserum against chicken hydroxyindole- $O$-methyltransferase reacts with the enzyme from pineal gland and retina and labels pineal modified photoreceptors. Mol. Brain Res. 4: 53-61.

Wainwright, S. D., and L. K. Wainwright (1980) Regulation of the cycle in chick pineal serotonin $\mathrm{N}$-acetyltransferase activity in vitro by light. J. Neurochem. 35: 451-457.

Wainwright, S. D., and L. K. Wainwright (1981) Regulation of chick pineal serotonin- $\mathrm{N}$-acetyltransferase activity by light and extra-pineal factor(s). In Pineal Function, C. D. Matthews and R. F. Seamark, eds., pp. 199-210, Elsevier/North-Holland, Amsterdam.

Wiechmann, A. F., D. Bok, and J. Horwitz (1986) Localization of melatonin synthesis and binding in the vertebrate retina. In Pineal and Retinal Relationships, P. J. O'Brien and D. C. Klein, eds., pp. 151-183, Academic, New York.

Wolf, K., and M. C. Quimby (1969) Fish cell and tissue culture. In Fish Physiology, vol. 3, W. S. Hoar and D. J. Randall, eds., pp. 253 305, Academic, New York.

Zatz, M., D. A. Mullen, and J. R. Moskal (1988) Photoendocrine transduction in cultured chick pineal cells: Effects of light, dark, and potassium on the melatonin rhythm. Brain Res. 438: 199-215. 